\title{
Programproduktion som Kritisk Teori - eller tv-teksten som industriel iscenesættelse
}

\author{
AfJohn Caldwell
}

Denne artikel peger på nødvendigheden af en revurdering af den tre-delte model, som Fiske og Gripsrud har fremfort, ved at vise, hvorledes 'sekundere' og 'tertiare' tv-tekster uafladeligt bevager sig eller rejser hen imod en 'primer' tekstuel status $i$ det amerikanske multikanals-»flow». En detaljeret gennemgang af industriens tekstuelle praksis - programbegivenheder, network-branding, kanallogoer, filmene bag filmen, pressemateriale på video, salgsmateriale og tilgransende digitale medier - viser hvorledes industrien teoretiserer sine egne vilkår direkte på skermen, og dermed også hvordan publikum vejledes igennem en sådan offentlig cirkulation af »insider-viden om tv-systemet. Artiklen er oversat af Henrik Bødker

Når tv som følge af både deregulering og den globale distribution af programmer i stigende grad kan karakteriseres som et multikanal-»flow «, bliver selve forestillingen om en program-»tekst « problematisk - og det på en måde, der rækker ud over de forestillinger om intertekstualitet, som har været fremført som en del af det postmoderne (Jameson, 1983; Lyotard, 1984; Foster, 1985; White, 1985; Stam, 1992). ${ }^{1}$ Med visse undtagelser (Corner et. al, 1990; Gripsrud, 1995; Jensen, 1995) er der tradition for, at akademiske studier af tv har holdt »kontekstuelle« aspekter (medier og samfund, effekt/påvirkning og økonomiske aspekter) adskilt fra »tekstuelle« analyser (semiotik, narratologi, og kritiske studier). I Nordamerika har denne opdeling af feltet afspejlet sig institutionelt, således at den påvirker den måde, hvorpå viden om tv reproduceres inden for universiteterne. Skønt »cultural studies« på sin vis peger frem imod en forening af de to lejre, er det yderst sjældent, at man fra de kontekst-centrerede universitetsmiljøer med rødder i studiet af massemedier og kommunikation bevæger sig ind på det hermeneutiske felt, der kendetegner den tekst-fokuserede tv-forskning, som er udsprunget af den filmanalytiske tradition. ${ }^{2}$ Denne arbejdsdeling var måske fornuftig nok, dengang de tre amerikanske tv-networks udgjorde et forholdsvist samlet »masse«-medium, men synes til gengæld at være temmelig snæversynet set i lyset af de iøjnefaldende forandringer i henvendelsesform og udtryk, der præger mange nyere programtyper. Selv om »narrow-casting « og niche-marketing på nuværende tidspunkt ser ud til fortrinsvis at kendetegne situationen i USA (hvor mange hjem nu kan vælge imellem over 100 kabel- og satellitkanaler), er idealet om et uendeligt antal valgmuligheder også blevet en forretningsmæssig drivkraft på den internationale arena. Multinationale selskaber (Viacom, Newscorp, SkyTV, Time-Warner etc.) er således i færd med at »åbne« tv-»markeder« i lande, der indtil nu har begrænset medieudbuddet gennem en eller anden form for central styring. I den industrielle form, der i dag er fremherskende i USA, hænger udtryksmæssig heterogenitet næsten uløseligt sammen med en spredning over flere kanaler. Og eftersom der investeres flittigt i både stilistisk spredning og flerkanals-leverance, er en fornyet kritisk interesse for tv-teksten både problematisk og nødvendig.

Som følge af disse nye tendenser bør følgende tre punkter fremhæves: 1) tv-forskningen bliver nødt til at erkende den industrielle logik bag mange af de nye programpermutationer, 2) mange nuværende tekstformater er i realiteten industriens iscenesættelser af den bagvedliggende kontekst, og 
3) tv's industrielle diskurser kan dermed ses som både en fremvisning af kulturelle kompetencer og et engagement i kritiske og teoretiske spørgsmål. Den omformning af forholdet mellem tekst og kontekst, som jeg netop har påpeget, undergraver således samtidig en anden feteret intellektuel opdeling, nemlig den imellem »teori« og »produktion«. En indgående undersøgelse af det væld af industrielle ikoner, tekster og ritualer, der kendetegner tvverdens produktions-»kultur « - mit overordnede og egentlige mål i denne artikel - peger på, at produktionsmiljøer (grupper af folk, der er kommercielt og socialt forbundne gennem lignende kompetencer og produktionsformer) vedvarende er involverede i overvejelser af kritisk, æstetisk og teoretisk karakter. Langt fra at være noget, som akademiske forskere har eneret på, er det at »teoretisere« nu også en proces, som tv-industrien stiller offentligt til skue på skærmen. Denne aktivitet kan måske ses som en slags »lokal viden« (Geertz, 1983), »allegorisk maskineri« (Boon, 1986) eller »lav-teori« (Caldwell, 1994), som den også er blevet benævnt. Industriens tilbøjelighed til dekonstruktion og refleksivitet kalder jeg for »kritisk produktions-praksis«. Tv-forskere burde ikke ignorere de processer, hvorigennem denne lave teori - om medierne af medierne - medvirker til at begrænse betydningsdannelsen og derved også bidrager til at styre de nydelsesbehov, som den elektroniske kultur opfylder hos forbrugerne.

\section{Industriens tekstuelle praksis}

Far from being writers ... readers are travelers; they move across lands belonging to someone else, like nomads poaching their way across fields they did not write, despoiling the wealth ... to enjoy it themselves.

- Michel de Certeau, citeret i Jenkins (1992).

Med udgangspunkt i, hvad der efterhånden må betegnes som en slags teoretisk ortodoksi, hylder de Certeau og Jenkins den modstandsdygtige læser, hvis aktivitet de betegner som en slags »krybskytteri«. Hvis man imidlertid udskifter »læser« med »tv-producer« i de Certeaus tekst, forbliver glorificeringen i og for sig lige så vedkommende. Men hvordan kan en producer inden for et af networkene anskues som en form for uregerlig »modstand«? Dette spørgsmål vil blive belyst igennem to mere generelle, men relaterede problemstillin- ger: de industrielle teksters kulturelle vandring; og de tærskelpositioner, som tv-industriens folk befinder sig i. Det skal først og fremmest fremhæves, at den tre-delte, tekstuelle taksonomi, foreslået af Fiske (1987) og videreudviklet af Gripsrud (1995) - med »primær, sekundær og tertiær« som adskilte tekstuelle kasser - forekommer unødigt simpel set $i$ lyset af det righoldige udbud af diskursive og lavteoretiske former, der både krydser og definerer det kontinuum, som forbinder den industrielle kontekst (traditionelt set defineret som teknologi, økonomi og produktion) og seerens tv-skærm (underholdningsprogrammet). Hvis der er noget, det er lykkedes tv-industrien at beherske midt $\mathrm{i}$ den seneste tids hurtige forandringer inden for både udtryksform og distribution, så er det evnen til at overdænge både produktions- og seerkulturer med mangfoldige, sekundære og tertiære produktionstekster: filmene bag filmene, salgs- og demobånd, pressemateriale på video, syndikerede underholdningsindslag og aktualitetsrapporter fra show-business-verdenen. Det er disse former for tekster, som jeg her vil fokusere på, og som i det følgende vil blive set som både teoretiske diskurser og terapeutiske udfoldelser, der i høj grad også er rettet imod industriens programmedarbejdere, usikre samarbejdspartnere, indkøbschefer og fusions-mindede topledere.

Det skal også pointeres, at en nærmere analyse af de udsendelser, der rent faktisk er blevet til med afsæt i de sekundære og industrielle tekster - der dagligt spyes ud PR maskiner og marketingsafdelinger - peger på, at det paradigme om publikums-»ritualer«/»aktiviteter«, der i de seneste år er blevet feteret inden for både kritisk teori og »cultural studies«, også kan finde anvendelse i relation til, hvad der sker i industrien. Så forskellige teorier som »krybskytteri« (omtalt ovenfor), »modstand« og »mod-læsninger« (Fiske, 1987), og »tærskelpositioner« - beskrevet og uddybet af Victor Turner (1986), Newcomb and Hirsch (1983), Dayan og Katz (1992) - har alle været med til at aktivere publikum, der tidligere var udvisket eller overset af både tekstanalysen og undersøgelser af kommunikationseffekter. Mens disse begreber har været med til at rette op på den pessimistiske slagside forårsaget af tidligere tiders ideologiske »top-down« studier af tv, udgør de samtidig en heuristisk bagage, der har tendens til at sløre de kulturelle og identitetsrelaterede ritualer, som dagligt udspilles inden for den industrielle 
horisont. Folk inden for industrien er konstant på »krybskytteri«, »medierer« regelmæssigt deres identiteter og navigerer ofte ud og ind imellem »tærskel-overskridende« identitetsritualer. Femhundrede-kanals universet (de nuværende multinationale medieselskabers officielle drøm) har endog fundet en måde at klemme »det at tale fra periferien « - en undergravende taktik, der benyttes af dem uden adgang til mere officielle talerør - med ind i forretningsmyten om væksten som forudbestemt skæbne. Eller sagt på en anden måde: bell hooks møder Viacom i det tillidsvækkende scenario, der udspilles i cyberspace efter networkene; og Viacom vinder. ${ }^{\text {a) }}$

Der er imidlertid ikke meget at opnå ved at anskue disse kulturelle og teoretiske ritualer i industrien som blot indlysende eller uundgåelige former for "genindvinding «. ${ }^{3}$ Hvis man reducerer denne form for »krybskytteri«, der finder sted i industrien, til strategiske modtræk mod grove og usle forsøg på meningsappropriation, reduceres denne aktivitet til noget, der kan indpasses på den overforsimplede menu over velkendte modsætninger (dominerende/dominerede; indenfor/udenfor; god/dårlig) - polære dikotomier, der er forudsat i tidligere teorier om »kulturindustrien « (Adorno og Horkheimer, 1944). Industrien er ikke blot en pansret forretningsbunker, der higer efter at opnå en homogeniserende dominans eller at blokere for alle forandringer. Totaliserende teorier, der henviser til en uundgåelig »genindvinding«, tilskriver blot industrien mere determinerende autoritet, end den har eller fortjener. Programmedarbejdere sidder også på den anden side af skærmen, $o g$ viden cirkulerer i begge retninger. Industriens »indkodere« er samtidig »afkodere«. Den dagligdagserfaring, de opnår ved konstant at afkode kultur i al almindelighed, må nødvendigvis komme til at præge hvert led i den indkodning, der finder sted i produktionen. Der er således et utal af brud i den proces, hvorigennem industrien bestandigt navigerer og lav-teoretiserer. Cirkulationen og den kommercielle udveksling af teoretisk viden $i$ et multikanals-univers skaber således en ikke uvæsentlig ustabilitet, en ustabilitet, der åbner for et væld af muligheder - måske ikke så meget for direkte former for modstand udefra, men snarere for interne aktiviteter, der har til hensigt at fremskynde en forretningsmæssig krise. En mere systematisk analyse af disse sekundære tekster og industrielle teoretiseringer kan i tilgift måske pege på muligheder for både modstand og forandring $\mathrm{i}$ det, der af mange er blevet kaldt "post-network" æraen.

\section{En taksonomi over granseoverskridende tekster}

Det er på mange måder formålstjenligt at kortlægge industriens tekstuelle praksis ved hjælp af den brede vifte af forskellige grupperinger af levende billeder, der produceres og cirkuleres i og omkring produktionen af tv's primære tekster, programmerne. I den følgende analyse vil denne række af forskellige former blive anskueliggjort i relation til tre overordnede kredsløb: 1) de industrielle teoretiseringer, der en indlejret i broadcast og »cablecast« primetime-udsendelser; 2) de sekundære teoretiseringer, der identificerer sig selv som sådanne, men som stadig indgår i sendefladen på lige fod med de primære programtekster, og til sidst 3) de sekundære teoretiseringer, der udenfor den ordinære konstellation eller programlægning af primære programtekster - cirkulerer i form af levende billeder på og omkring branchens messer, konferencer og lignende og/eller som elektronisk medierede former. Jeg begynder min oversigt med at se nærmere på den kritiske tekstuelle praksis, der efterhånden er ret udbredt inden for programafdelinger (stilistiske øvelser i form af specielle episoder, program»begivenheder «); herefter bevæger jeg mig ind i det næste kredsløb for at undersøge sekundære teoretiseringer (koblinger mellem nyheder og fiktionsprogrammer, kanal»branding«, og filmene bag filmen), mens jeg slutter af i det tredje kredsløb med nogle overvejelser om supplerende tekstuelle former (pressemateriale på video og netsteder).

En oversigt over disse tekstformer vil, håber jeg, gøre det klart, at disse tekstuelle og industrielle teoretiseringer (om tv af tv) ikke kan karakteriseres ved nogen essentiel, formel eller generisk egenskab, men derimod ved deres flydende karakter, deres mobilitet ind og ud af skærmen, og ved deres »bevægelser« imellem sekundære, primære og tertiære stadier. Ethvert forsøg på at forklare den industrielle eller kulturelle logik, der kendetegner disse teoretiseringer på skærmen, må derfor også tage højde for hvordan disse tekster er i konstant bevægelse hen over traditionelle grænseskel. 


\section{Primetime pædagogik: stilistiske udfoldelser set som kulturelle medieringer}

Jeg indleder med et eksempel på en forholdsvis almindelig måde, hvorpå tv i kritisk forstand medierer kultur. Det drejer sig om en episode fra en serie, der kørte fra sidst i 1960'erne, hvori medarbejderne igennem en selvbevidst brug af produktionsformer og - udtryk forholdte sig til kulturelle forandringer. ${ }^{4}$ En af de bedste måder at forstå industriens tekstuelle praksis på og forstå, hvad der er på spil i den lave teori, er at se på, hvordan industrien har positioneret sig i relation til og reflekteret over en problematik, der har været tæt knyttet til selve produktionsarbejdet, nemlig spørgsmålet om udtryksmåde i al almindelighed og begreberne »kunst« og »filmkunst«i særdeleshed. En tilbundsgående undersøgelse af amerikanske tv-programmer fra halvtredserne og tresserne, der eksplicit forholdte sig til begreberne kunst, udtryksform og finkultur, peger på to tilbagevendende primetimetroper. Først og fremmest har både avant-garden og finkulturen konsekvent været sammenblandet med forskellige radikale aberrationer - afvigelser af seksuel, racemæssig eller anden karakter. Og dernæst blev disse problemstillinger typisk fortolket med udgangspunkt i den moralske geografi, der udgår fra midten af Amerika, og i relation til hvilken den æstetiske trussel/tillokkelse fandtes i øst (New York og Europa i halvtresserne) og i vest (Los Angeles i tresserne). Ved første øjekast så den episode af Dragnet, der hed»Blue Boy« (1967), ud til at gå på tværs af breddegradden i denne æstetiske/ moralske geografi. Men på et andet plan ser episoden snarere ud til at være endnu et eksempel på primetime-tv's opportunistiske appropriationer af populærkulturen: politibetjent Joe Friday filosoferer højlydt for sin makker: »det er græs«, mens de er i færd med at anholde en flok uregerlige æstetikere. Et nærmere eftersyn peger dog på, at dette afsnit snarere skal ses som et udpræget offentligt ritual, hvorigennem selve produktionsprocessen indtager, retfærdiggør og kodificerer en alternativ og rammende produktionsform. I forlængelse af Geertz (1973) er det måske på sin plads at se denne udfoldelse som et udtryk for industriens tanker ikke kun om protestbevægelsernes og hippiekulturens spøgelse, men i lige så høj grad om sig selv. En udlægning af Dragnet som en primetime spydspids for lov-og-orden-konservatismen (Marc, 1992,
136) vil have svært ved at forklare den fortolkende forandring, som programserien gennemgik i sin levetid. ${ }^{5}$ »Centrum « for seriens fiktive univers er rigtig nok eksplicit identificeret som den normale, moralske kerne- og forstadsfamilie. Og familien - lige så vel som deres surrogate forældreautoritet i form af kriminalbetjentene fra Los Angeles politi - er begrænset af et verdensbillede tonet i sort, hvidt og gråt. Men både den moralske geografi og sammensmeltningen af kunst og afvigelse, der var så udbredt i halvtredserne og tresserne, har imidlertid ændret sig. Den udbredte øst-vest akse - Europa-New York-midteregionen - Los Angeles - er blevet vendt til en vertikal dimension: seriens velkendte forstadsmiljø spreder sig som et tæppe over de lavtliggende områder, mens den æstetiske degeneration ligger på lur oppe i Hollywoods bakker. Selve Hollywood er forvandlet til den flamme, der drager myggen (eller den fortabte søn) ind imod hippiekulturen, abstrakt kunst og hallucinogene stoffer. Selv om det ikke lykkedes kriminalbetjent Friday og hans makker at rede den oprørske digter fra selvudslettelsen, er serien ikke udtryk for en simpel, forudbestemt fordømmelse af narkokulturen.

Set i lyset af at episoden var produceret til den efterårssæson, der efterfulgte den berygtede (men ikke længere oprørske) »Summer of love«, er det faktisk muligt at se den som et meget oprigtigt bud på et undervisningsprogram. Eller med andre ord som et primetime-produkt, som slog knuder på sig selv for at »oplyse« familien og børnene om de taksonomier, myter og farer, der er forbundet med ulovlige stoffer. Disse emner var i slutningen af 1967 trods alt noget, der både var overskriftsstof i de store ugeblade og placeret på lærer- og forældreorganisationernes (PTA's) dagsorden. ${ }^{6}$ Den ironi, der i postmodernismens bakspejl ser temmelig overdreven ud, skygger faktisk for, at programmet er fyldt med »nyttige« råd om sundhed og hygiejne i forbindelse med brugen af marihuana og LSD. Som en del af plottet i programmet beder betjent Friday nogle »laboratorieeksperter« om at forklare sådanne ting. Deres medlevende, hastige videnskabelige mini-forelæsninger fungerer som leksikonopslag, der med en vis desperation synes proppet ind i flere en- og to-minutters scener. Resultatet bliver en slags brugermanual for forældre, der har behov for at holde sig ajour med den modkulturelle narko-slang, som bruges af kvarterets unge. 
Programmet som helhed er derfor langt fra at være en refleksagtig afvisning af narkokulturen, men er derimod et seriøst forsøg på at reagere på, navigere i forhold til og forklare denne kultur i et mere acceptabelt sprog. Og det er »kunsten«, der leverer dette sprog til Amerikas middelklasse. I en bizar, (a)historisk blanding - der forbinder avantgarden, malingssniffende abstrakte kunstnere, båndet musik, der afspilles baglæns, og halvtressernes »beat«-digtning - bliver de involverede og velinformerede produktionsmedarbejdere nærmest pålagt at forholde sig stilistisk til truslen. Uortodokse røde og grønne scenelys - en dårlig efterligning af look'et fra undergrundsfilm - afskærmer de afvigende udskud fra middelklassen i varme fluorescerende farver. Længe før MTM og Lears »seriøse« sit-coms i begyndelsen af halvfjerdserne tager Dragnet således fat i vigtige betydningsfulde emner med en række sociale implikationer. Længe for MTM $^{\text {b) }}$ er Dragnet således i færd med at levere forklaringer og undervisning til publikum i deres hjem. Som en forholdsvis konventionel sit-com formidlede Dragnet viden om Hollywood, ungdomskulturen og mode til dem, der inden længe ville iklæde sig modkulturen i mere acceptable former og forbrugsgoder: bukser med svaj og perlekæder. På sin vis var dette på en og samme tid en populær udlægning af og tilgang til moderne kunst, en indføring i filmens univers og skoleundervisning i sundhed for de ældste klasser. Dette er således et ret typisk eksempel på, hvordan produktionsmiljøet kan fungere som et mellemled og en kulturel navigatør, der producerer programmer, som så at sige tager publikum derhjemme $\mathrm{i}$ hånden. Men medieringen fungerer selvsagt i begge retninger: afvigende kulturelle praksisser forsyner samtidig produktionsselskabet Mark VII Productions - kendt for sine rutineprægede, lav-budgets og fabriksagtige forhold - med de udtryk, der er nødvendige for at rationalisere, systematisere og normalisere dets eget lidt tøvende forsøg med fornyende produktionsformer. Selv en serie som Dragnet kan således også ses som et særdeles offentligt udtryk, igennem hvilket produktionsmedarbejderne gav et visuelt bud på forholdet mellem produktionen og den omkringliggende kultur.

\section{Program-»begivenheder«: konstruktionen af en stilistisk forkant}

To årtier senere, i firserne, der i amerikansk tv kan karakteriseres som topklasse eller »signatur«-producernes glansperiode, skilte Stephen Bocho sig klart ud fra mængden. ${ }^{c)}$ Bocho blev faktisk en slags skydeskive for tv-kritikere og klagende producere/manuskriptforfattere, hvis programmer aldrig blev mødt med den samme network-understøttede risikovillighed, som Bocho's network-mæcener havde tildelt ham i 1981 i forbindelse med Hill Street Blues og i 1986 med L.A. Law. I fagblade og blandt journalister var der en udpræget opfattelse af, at CopRock skulle blive kronen på Bochos kunstneriske udvikling. Bocho var på forkant med udviklingen; og CopRock var udset til at »sprede den stilistiske vifte« længere ud end nogensinde før. Network-postmodernismens guldalder stod lige for døren parat til at spille sit »kvalitets«-trumfkort ud mod kabelstationernes inferiøre programindhold.

Men på trods af den hæsblæsende marketingskampagne, der gik forud for serien, og som på forhånd teoretiserede dens æstetiske virkninger for det store publikum, blev serien, da den endelig fik premiere, først mødt med forvirring og dernæst med latterliggørelse. Den sammensathed, der kendetegnende serien, blev mere og mere udpræget, hvorefter den gik ned med et brag. Faktisk var seriens egentlige substans - en direkte følge af den højtgearede æstetik og gruppebaserede tekstproduktion, der dengang dominerede Hollywood - allerede formidlet direkte til publikum i løbet af foråret og sommeren, og det uden det rod $o g$ forviklinger, der ville være forbundet med først at skulle vise serien. ${ }^{7}$ En fortælling om storbyens politi fortalt i afsnit af en times varighed blev klonet som en musical for dernæst at blive overstrøet med alle de kvalitetstegn, der forbindes med høje produktionsomkostninger, og alle de populærkulturelle referencer, som den prestigefyldte produktionsbemanding kunne mønstre. Dramafyldte sekvenser, som blev vist, inden seriens titel tonede frem, blev hurtigt afløst af et testosteron-drevet »steadicam" og filmiske ornamenter, hvilket igen førte videre til bizarre, multi-plan-scener, i hvilke fiktive figurer, »rigtige« læderklædte og midaldrende skuespillere med tekstforfatteren Randy Newman i spidsen, og middelmådige studiemu- 
sikere i en skønsom blanding alle messede den samme rytme. Den forudbestemte relevans, der udsprang af kendskab til producenten - en forholden sig til byen, raceproblematikken og samfundet - forsvandt stille og roligt op i den blå luft, alt imens seerne forundrede kløede sig i hovedet. Åbenbart var det det, der skete, når Hollywood bad hvide WGA [Writers Guild of America] manuskriptforfattere om at skrive sort »rap«-musik. ${ }^{8}$ Denne højt-profilerede serie markerede faktisk et vendepunkt i Hollywoods æstetiske udvikling. Økonomisk nedgang og reality-tv fulgte i kølvandet på sen-firsernes fokus på højtprofilerede produktionsselskaber, og CopRock udstillede marketing som det egentlige udgangspunkt for både tekstens og programmets tilblivelse. På sin vis kan man sige, at marketingskampagnen på et overordnet plan determinerede serien som en blandingsgenre, hvilket igen bestemte de enkelte scener i selve serien. Den store rolle, som marketing her spillede, var et klart udtryk for de økonomiske interesser, der drev det Hollywood-baserede tv ud i risikable satsninger i slutningen af 1980'erne og begyndelsen af 1990'erne. CopRock fremstår som en drilagtig fordrejning af Stuart Halls ideer om en »oppositionel« læsning eller mod-læsning. Det eksplicit oppositionelle var jo netop det »offentlige« afsæt, der lå til grund for både den altafgørende marketingskampagne og udsendelsens narrative form.

\section{Koblinger mellem fiktion og nyheder - " nnews tie-ins»}

Selv den jævnt opmærksomme seer kan i løbet af "sweep weeks « ${ }^{9}$ ikke undgå at lægge mærke til den iver, hvormed de lokale stationer, der er tilknyttet de landsdækkende network, prøver at kæde deres nyhedsudsendelser sammen med networkenes programflade for at skabe tv-baserede »begivenheder«. Selvom »seriøse« journalister nok vil føle afsky ved denne form for sammenkædning eller afsmitning, er det dog en praksis, der er mere end blot sensationelle stunts eller hjerteløs udnyttelse af nogle forhåndenværende menneskelige tragedier. Dette at fiktionsprogrammer og networkenes stjerneskuespillere finder vej ind i nyhedsudsendelserne er faktisk så udbredt, at man kunne påstå, at sådanne sammenkædninger faktisk udgør den mest fremherskende genre i lokale nyhedsudsendelser. ${ }^{10}$ I forlængelse heraf er det værd at bemærke, at disse sammenkoblinger også passer fint ind i de kriterier, som jeg skitserede i forbindelse med den lave teori: selvom de tilknyttede stationer igennem disse sammenkoblinger bevidst forsøger at drage fordel af networkets publikum i de såkaldte »sweep weeks«, er de samtidig del af en offentlig proces, hvorigennem viden om tv-industrien formidles videre til seerne.

Da nyhedsoplæserne på KNBC/Los Angeles tildængede deres sene nyhedsudsendelser $\mathrm{i} »$ the sweep weeks« med en række koblinger til serien E.R., som de netop havde haft enorm succes med i 1995, var det ikke kun resultatet af en grådig higen efter en hurtig genvej til omtale. Ved at lade en række afbrydelser, hvor E.R. blev promoveret, efterfølge af »nyheds«-informationer om E.R. - heriblandt noget om den ledende skuespiller og drømmehelt George Clooney, en af de femlinger, der havde ageret nyfødt $\mathrm{i}$ aftenens afsnit, samt noget om dette afsnits gæste-«auteur«, instruktør/ provokatør Quentin Tarantino - var nyhedsfolkene faktisk i færd med at hylde og samtidig konstruere en Hollywoodsk »storfamilie« i seernes bevidsthed. Tarantino, strøget til tops med afsæt i Reservoir Dogs og den netop stort-opslåede og omdiskuterede Pulp Fiction, var selvsagt årets mest oplagte bud på en kult-instruktør. Tarantino var Cannes, undergrundskultur, den slemme dreng og Hollywoods bonede gulve i én og samme person. Men her, i KNBC's lidt sludrende nyhedsindslag, luntede Tarantino ikke bare ærbødigt rundt i KNBC's lokaler, hans ligefremme og afslappede svar til reporterne gav også indtryk af en jævn mand, der elskede tv i almindelighed og E.R. i særdeleshed.

Denne type medierende tekst vender således op og ned på en af Hollywoods dybt forankrede og mest dominerende høj-lav hierarkier. De formelt påklædte, friserede og altid fattede nyhedsoplæsere funderer en del over, at den utraditionelle og nyskabende Tarantino - for de flestes vedkommende kendt som en »hot-shot« film auteur på forkant med den stilistiske udvikling - med glæde havde kastet sig over den uventede chance for at instruere tv, og at »deres« E.R. faktisk var hans yndlingsprogram. »Det var ikke noget særligt«, hævdede han lidt forlegent - »det var bare et par instruktør-kommentarer hist og pist«. Denne selvudslettende indstilling overlod det til folk blandt publikum at fange Tarantinos stilistiske kendetegn, blandt andet et større konstruktionsværktøj 
af metal, der var efterladt stikkende ud af hjertet på en patient - et blodigt billede af en dødeligt såret mand liggende på en båre, der totalt dominerede denne scenes centrum. De rigtige stjerner i denne rekonstruktion af Tarantino og hans konstruktionsværktøj var selvsagt de lokale nyhedsoplæsere Moyer og Lange - der med fuld kontrol over studiet var i stand til at citere kultfilm og elskværdigt villige til at modtage Tarantinos hyldest til tv-mediet. Moyer og Lange var tilsyneladende virkelige kendere af det »hippe«. Samtidig med at den stilistiske forkant er indflettet i deres medierende tekstuelle materiale, var disse stjerne-oplæsere i færd med at blæse lokale nyheder op på et nationalt niveau: denne sammenkædning bliver således til en nyhed om en network-familie eller måske om selve Hollywood. Der er åbenlyse fordele ved denne form for forceret symbolsk og institutionel sammensmeltning. Koblinger imellem nyheder og fiktionsprogrammer, der analyserer og belærer publikum om industriens struktur, er ikke helt uden hold i virkeligheden; disse nyhedsimpresarioer teoretiserer rent faktisk om reelle økonomiske og juridiske relationer mellem de kommercielle enheder i Hollywood. De implicerede forsøger at overbevise sig selv, alt imens deres firmaer manøvrerer med komplicerede og virkelige produktionsrelationer.

\section{Network som markevare}

Da CNN, MTV, Lifetime, BET og andre kabelstationer i begyndelsen af 1980'erne tog konkurrencen op med de eksisterende kanaler, affærdigede networkene offentligt og med overbærende og selvtilfreds mine denne trussel. Set fra networkenes tredelte verden indså man tilsyneladende ikke, at de nye kabelstationers fremmarch var tæt knyttet til det at kunne identificere en mærkevare, noget der i de efterfølgende årtier ville blive en vigtig del af networkenes egen overlevelsestaktik. Visuelle logoer indsat i kabelstationernes programmer kom i multikanalsflimmeret til at fungere som væsentlige holdepunkter - det gjaldt f.eks. for den generelle kabelstation USA network, og for yuppie boutique nicher såsom VH-1 og Lifetime. Mens de indsatte logoer på C-Span forsat ligner identifikationsnummeret på et overvågningskamera, har andre kabelstationer - især dem med forbindelse til Viacom - udviklet logoet til meget mere end blot et pejlemærke for kanalvalg. Især MTV har omformet deres logoer og identifikationsmærker til en videografisk scene og et flertydigt tegn, der er under konstant udvikling. Ved at bede en række kunstnere, designere og leranimatorer om at presse MTV-logoet til sine kanoniske grænser, kom stationens visuelle varemærke til at fremstå som en egentlig del af programfladen - som en slags overdetermineret stilistik og rensende ritual, der med faste mellemrum optog hele skærmen. Med sin firmaidentitet tæt knyttet til bestemte kunstnere og designere var stationen således i færd med at koreografere sin identitet på baggrund af både overtoner af smagskultur og en umådeholden selvbevidsthed. Disse overspændte videografiske logoer kom med tiden til at indeholde skudsalver af hurtigt-skiftende MTV'er, der i hjernebedøvende eksplosioner på ti sekunder genopførte den vestlige verdens kunsthistorie - fra den Palæolitiske tid til post postmodernismen. Det »æstetiske« påvirkede således ikke kun kabelstationernes industrielle forretningsgang, men var også noget som sansemæssigt kunne inhaleres i løbet af den tid, det tager seeren at finde fjernbetjeningen.

At der er behov for på en effektiv måde at etablere mærkevarer, er nu en udbredt holdning i industriens forskellige fora og publikationer. De »boutique« digitale medieselskaber, der har været med til at etablere det nye Hollywood (ved at levere den teknik, der har gjort det muligt for de store medieorganisationer at opnå stilistisk individualisering igennem køb af grafik, animation og special effects), beklager sig nu over de formidable økonomiske dimensioner, der følger med det at være på samme tid anderledes og lille. ${ }^{11}$ Hollywoods store - Warner Brothers, Disney, MGM $\mathrm{og}$ andre - har simpelthen flere kræfter, når det drejer sig om at etablere en mærkevare, der signalerer kvalitet på det globale mediemarked. Dette krav om mærkevarer er for en stor dels vedkommende affødt af en fornemmelse af, at der ikke er seere nok til alle - dvs. at der ikke er nok til, at man kan bibeholde sit overskud, samtidig med at man deler med konkurrenterne. 


\section{Identifikation/logoer:} Tilblivelsen af "familiare» bånd imellem networkene og deres tilknyttede stationer

Den hovne selvsikkerhed, som networkene oprindeligt udviste med hensyn til deres overlegne evner i det nye multikanal-»flow«, var i midten af 1990'erne forvandlet til en krisesituation. Efter at have mistet betydelige markedsandele havde de tre store network nu behov for ikke bare at gøre publikum, men også industrien opmærksom på de fordele, der er ved en network-»familie«. Networkene befandt sig således i en kritisk situation, hvor den retorik, der gennemsyrede branchen, enten pegede i retning af opløsning eller sammenlægning. I 1995 og 1996 gik NBC til modangreb ved at låne præsident Bushs ellers meget kritiserede myte om de »tusind lyspunkter«. Det havde ved nærmere undersøgelser vist sig, at de traditionelle fire-bogstavs forkortelser simpelthen var for komplicerede at huske for de fleste. Og hvad gjorde man så? De lokale stationer, der var ejede af de nationale networks, skulle droppe »K'erne« og »W'erne« i nationale udsendelser (som f. eks i $» \mathrm{KNBC}$, Burbank«) og i stedet bruge NBC kanal-nummeret (»NBC-4, Burbank«) som et mere enkelt tegn og fælles logo. De udsendelser, hvori networket og/eller de tilknyttede stationer på tværs af nationen profilerede sig i denne periode, viser, i hvor høj grad usikkerhed om fremtiden påvirkede selskabets aktiviteter. ${ }^{12}$ I et eksempel glider kameraet hen over en grafisk fremstilling af USA i ensartede prikker, hvorefter hundredvis af lyspunkter pludselig markerer networkets »214 tilknyttede stationer spredt ud over nationen, inklusiv KJPH-2, Tulsa, Oklahoma«. Denne kampagne kom logisk nok lige efter den meget omtalte »flugt« fra CBS, da en række stationer, der havde været tilknyttet gennem længere tid - en slags »forrædere« mod network-forbindelsen - valgte at satse på de gode udsigter og mere hippe programlægning hos Fox, det nye og fjerde network. NBC's forherligelse og symbolske konstruktion af en network - «familie« kan i det lys ses som en slags forebyggende forretnings-taktisk træk, som energisk forsøgte at genskabe den aura, der havde været omkring networkenes autoritet og kvalitet. Ikke siden 1950'erne havde det været nødvendigt for networkene at bruge så meget energi på at overbevise seerne og stationerne om fordelene ved tilknytningen til et nationalt network. Denne type medierende video-tekst fungerer således som en slags kortfattet brancherapport for tilknyttede men ængstelige stationer, der måtte have overvejet at springe fra borde. Denne top-down model for prestigeprogrammer - der inkluderer Hollywood tv og network-nyheder - prøver altid at garantere trivslen for de tilknyttede stationer, der sender ude i provinserne.

Den slags aggressive og hårdhændede forsøg på at begrænse skaderne, som kommer til udtryk i disse spots, var del af en mere omfattende række af »fornyelser«i markedsføringen. NBC havde blandt andet også formået at få programproducenterne til at sætte NBC-logoet ind i selve programmerne. Dette udspil var rent faktisk en meget udspekuleret form for afpresning, idet programproducenterne i årevis havde beklaget sig over, at betalingerne fra networkene ikke var rimelige, altså, at de ikke svarede til de faktiske produktionsomkostninger. Disse omkostninger blev i sidste ende kun dækket ved, at noget af konsortiets overskud senere gik direkte til produktionsselskaberne. NBC pressede således deres partnere til at opstille fjernsynsudsendte billboards i programafsnit, som NBC kun delvist havde betalt for. NBC's finansielle langtidsudsigter var åbenbart både betydningsfulde og i bekneb nok til, at programudbyderne indså, at deres skæbner hang sammen med »sundheden« af det network, der oprindeligt havde introduceret deres programmer. Ved at eliminere de kommercielle afbrydelser imellem programmerne, og ved at kræve networklogoet sat ind i selve programmets narrative scener, kunne networkene love, at flere seere ville blive hængende fra program til program. Dette var programudbyderne selvsagt interesseret $\mathrm{i}$ - vel at mærke hvis networkene programsatte dem imellem attraktive programmer, der havde bevist deres tiltrækningskraft. Men det, der virkelig er bemærkelsesværdigt ved disse træk inden for programlægningen, er den bevidsthed, de afstedkommer i offentligheden om, at programudbydernes, networkenes og de tilknyttede stationers skæbne hænger uløseligt sammen. Både networkenes kampagne for en »familie af stationer « og taktikken med at indsætte logoer i selve de fortællende dele af programmerne er udtryk for den meget offentlige måde, hvorpå tv-industrien medierer og forholder sig til forandringer, selv om det formilder den usikkerhed, der præger industrien. 


\section{Pressemateriale på video og network "omlagninger"}

Katie Couric, værten i Today Show, annoncerede med et udtryk, der syntes at være indbegrebet af uafhængighed, at seerne netop stod for at skulle være vidner til networkets »mest gennemgribende omlægninger nogensinde « ${ }^{13}$ Visuelt bevis for, at noget var sket i den æstetiske praksis, der ellers kendetegnede networkene, fik man i det efterfølgende segment, som opsummerede NBC's kampagne fra 1994, hvis formål bestod i en gennemgribende opretning og revision af firmaets forretningslogo og identitet. Denne ændring var også startskuddet til en knopskydning af medierende videoformer, der alle var designet til at »styre« og følge denne revision til dørs i publikums bevidsthed. NBC's marketingsmaskine lod samtidig en overflod af medierende tekster, der både legitimerede og analyserede deres »nye« look og »attitude«, strømme ud i de forskellige programlægningscirkler.

Det ellers så sindige og ærværdige NBC hyrede nogle avantgardistiske kunstnere - hvad selskabet selv kaldte »de største navne i design og animation« - til at skitsere, konstruere, modellere og animere et »look« som udtrykte networkets nyfundne attitude. Mark Malmberg, computer-kunstnerguru bag cyberfilmen Lawnmover Man, introducerede en del Grateful Dead-elektronik i networket. David Daniels - »bad boy « kunstner for den kække vært Katie Couric, velanskrevet instruktør af musikvideoer og leranimation-spots for Honda - anbefalede ret anmassende sin network-produktion, som han kaldte »et psykedelisk farsbrød i bevægelse«. Peter Max, en aflagt popkunstner fra 1960'erne, der på ny var vakt til live, messede gentagne gange om de »frie tøjler«, som det fremsynede NBC havde givet ham til at udtrykke sig. Og maleren Joan Gratz trådte frem og beskrev networkets logo som elektronisk »impressionisme«.

Postmodernismens lidt mørkere side trådte også frem i fuldt flor gennem J.J. Seidelmeier og John Kricfalusi. Seidelmeier kreerede sit logo ud fra den hjernedøde, animerede »slacker«-æstetik fra Beavis and Butthead. Krifalusi, ophavsmand til den opblæste tegnefilmsæstetik fra Ren and Stimpy, drillede intervieweren, mens han forklarede publikum sin vision med network-påfuglen: »der kommer farvestrålende ting ud af dens bagdel«. For at fuldende den »bad boy«-agtige, avant-gardistiske skabelon for firmaets nye image tildelte NBC sendetid til to ikke-professionelle computergrafik-kunstnere, der risikovilligt pressede deres almindelige Macintosh-hjemmecomputere til det yderste. Meningen var klar. Publikum var »slemt«, men Fortune 100 NBC selskabet var »slemmere«. Selv da Kricfalusi ikke særligt oprigtigt påstod, at »jeg ved ikke, hvad hip er« (endnu en opdatering af Warhols »I don't care«-æstetik), viste NBC, at man nu rent faktisk var det hippes imperium. Her var end ikke brug for nogen tvivl på sig selv.

\section{Internet/Intertexts: "underholdning med mervardi"}

En af de primære måder, hvorpå industrien nu medierer viden om sig selv til publikum, er gennem en række netsteder (web-sider, bulletin boards, online chat begivenheder etc.). Disse steder giver for dem, der bevæger sig rundt på Internettet, angiveligt adgang til et væld af inside-materiale: interview med medvirkende og medarbejdere; still-billeder fra produktionen (noget som studiernes marketingsafdelinger aldrig ville tage sig tid til at sende til selv de mest interesserede seere); og »cyberchats « med program producere/skribenter såsom Chris Carter, der står bag $X$-files. Mange shows, f. eks $X$-Files og Xena: Warrior Princess, opfordrer ligefrem til input fra fans med hensyn til drejebog og karakterer. Disse bidrag udgør en slags drejebogsråmateriale, der kan indføjes i kommende afsnit. Producere på Fox fortalte at de havde ansat to unge kvinder i tyverne, der hverken havde noget papir på deres færdigheder og heller ikke nogen egentlig erfaring med at skrive manuskripter. De blev ansat udelukkende på baggrund af de små drejebogsbidder, som de havde sendt med e-post til producernes kontor. ${ }^{14}$ I takt med at den fysiske voldgrav, der tidligere holdt industrien adskilt fra seerne, er gået i opløsning, er der i dag mange producenter, der ligefrem efterlyser og opsøger seeren i cyberspace - snarere end det omvendte er tilfældet. I både »officielle« og »uofficielle« Internet fora og fansteder bliver viden om tv-shows således ofte medieret af industrien igennem de industri/publikum-grænseflader, der opstår via computeren. Sådanne anmodninger om viden fra seeren til industrien, og derpå følgende vedkendelse af seer-input på skærmen, altså en form for on-line, lavteoretisering, er langt fra en uengageret form for analyse. Dette er »dekonstruktion« uden for universitetet, en lav analyse, der aktivt ændrer objektet, den primære 
tekst, der analyseres. Hvis strukturalismen gjorde det af med det seende subjekt, og poststrukturalismen udslettede det skabende subjekt/forfatter/ producer, så genskaber og puster tv-industriens tilstedeværelse på Internettet nyt liv i dem begge ved en elektronisk kobling mellem publikum og producer. Selvom de elektroniske steder, som studierne producerer indtjener færre penge end de koster at lave, så vedbliver topledelsen med at retfærdiggøre dem som en slags »value added entertainment Altså, selv om serie-relaterede netsteder, CD'ere eller interaktive spil ikke giver noget større overskud, så er de med til at intensivere den værdifulde demografi, der eksisterer for show såsom $X$-Files, Friends eller E.R. Ved at puste liv i et eksisterende publikum gennem en forøgelse af deres forbrug, tilføjer disse elektroniske ledsagetekster en merværdi til den oprindelige serie, hvorved producere og studier kan forhøje deres reklameomsætning. ${ }^{15}$

\section{Faux-Teori/Faux-Historie}

Nutidigt tv »teoretiserer« ikke kun det på forkant, det hippe og det interaktive i fankulturen. Tvverden har endog nok intellektuel muskelkraft til samtidigt at dekonstruere den akademiske medieteori. Midt i den opblomstring af Brady-figuren, der skete på en række områder i 1995, kreerede Viacoms Nick-at-Nite en falsk 13-afsnits serie med titlen The Brady Chronicles, der blev udsendt i forbindelse med premieren på Brady: The Movie, (og hvis eneste udsendelse var en »diskussion« af den oprindelige serie The Brady Bunch, der blev sendt i 1970'erne). The Brady Chronicles var både en eksplicit parodi på den ellers så lovpriste Ken-Burns æstetik fra de kvalitetsdokumentarudsendelser som det høj-kulturelle PBS havde profileret sig på, og en bidende dekonstruktion af de medieforskere, der analyserer tv. En klog og faderlig fortællerstemme - lånt fra den zoologiske serie Nature, der længe havde kørt på PBS - forklarede i store træk de slående ligheder imellem Brady-familiens ideologiske verden og den amerikanske borgerkrig. Folkene på Nick-at-Nite fremdrog analytiske ligheder, der udviklede sig fra det surrealistiske til det skandaløse. Amerikanske historikere, sociologer og medie-psykologer var på skift på skærmen for at afdække den oprindelige series mange kulturelle gåder. Ja, det blev faktisk »påvist«, at The Brady Bunch inddrog feminisme, modkulturel politik og fædrelands-«konstruktion«, alt sammen igennem deres »terapeutiske« vision om Amerikas »healing «. d) Og rigtig nok, der på skærmen fremtonede de arkitektoniske blåtryk for denne sitcoms studieopbygning, der viste sig at have en »12-trins« trappe som den styrende metafor (altså, 12-trins terapi), en »figur«, ved hjælp af hvilken den tidligere Brady Bunch serie tilsyneladende havde forholdt sig til sin tids markante kulturelle omvæltninger. ${ }^{16}$ Christopher Lasch møder AA og Victor Turner i denne halv-times industrielle teoretisering om medieteorier. ${ }^{17}$

Det særlige bid, der var i denne ironi, der altså var mere end blot vittigheder eller tom, postmoderne pastiche, tydede på, at programmets produktionsmedarbejdere havde en vis viden om medievidenskab. De medvirkende tilførte således dette afsnit - for at bruge Bourdieus udtryk - et overskud af kulturel kapital, et overskud, der fik selv PBS’s højkulturelle Burns-æstetik til at se elementær og udpint ud (Bourdieu, 1983). The Brady Chronicles, udsendt på et nostalgisk kabelnetwork, til dels rettet mod børn, var stilistisk og teoretisk langt mere sofistikeret end det centrerede, nostalgiske subjekt og den minimalistiske, stilistiske følsomhed, der kendetegner den »højere« PBS smagskultur. Den lethed hvormed Viacom kastede sig ud i en sådan hip dekonstruktion samt i kulturhistorie og kritisk parodi - noget, der åbenbart nu er med til at definere mainstream tv - vendte fuldstændig om på Gans' standard-hierarki for smagskulturer (Gans, 1974). Burns og PBS var Kant'ske og begrænsede; »Brady« og Nick var poststrukturelle og karnevalske. For mig kom dette som en slags epifani, da jeg indså at »Brady« og Nicks anklager også var rettet mod mig selv. At analysere tv er jo hvad jeg beskæftiger mig med. The Brady Chronicles viste sig faktisk at være en slags ond drøm om konferenceoplæg, jeg tidligere havde præsenteret. Viacom-selskabet leverede en cultural-studies »læsning « - og de gjorde det bedre end de seriøse historikere hos PBS.

\section{Konklusion: Eksploderende kontekster/rejsende tekster}

No longer is promotion a secondary tactical device; it is now a primary marketing function enabling competitive positioning of stations, networks and systems in their markets ... Promotion 
is the indispensible tool for creating and exploiting differences.

$$
\text { - Susan Tyler Eastman (1991: 3) }
$$

Min hurtige overflyvning af tv-industriens teoretiske lavland kan måske virke lidt smagløs på dem, der stadig anser denne vifte af kontekstualiserende tekster som det rene og skære bras udspyet gennem tv-industriens salgsmaskiner af impresarioer stærkt tynget af diverse særinteresser. Der er dog en del overbevisende tegn på, at der er andre faktorer på spil: en af industriens væsentligste taktikker er nu at tilplastre hele befolkningen med disse mellemliggende tekster og blandings-»programmer«, der både er med til at styre forskellige udsendelsers mening, og som - iført den kritiske analyses overfrakke - har til formål at mediere viden om tv til/for seeren.

Her afslutningsvis er det værd at dvæle lidt ved de intellektuelle retninger i hvilke disse lav-teoretiske permutationer bevæger sig, og de udfordringer, de frembyder for medieteorien. På et niveau udfyldte Dragnet en forholdsvis konventionel funktion. Dens fortællende tekster fungerede tit som en slags primetime pædagogik, i dette tilfælde ved dens skønsomme blanding af sundheds-hygiejne-straffemæssige diskurser på en måde, der ville have gjort både Foucault og produktionspersonalet stolt. CopRock derimod beviste at marketingstekster kan opnå status af »master-codes«, der faktisk »skriver « programtekster. Dette var et logisk resultat af vores nuværende epoke i hvilken industrien presses til at udvikle serier ved hjælp af koncept-tænkningen udmøntet i to-minutters, talte »pitch«. Promotion-videoer - der ikke bare er visitkort - fungerer både som stilistiske og konceptuelle brugsmanualer, og som kritiske »steder« for tv's tekniske stampersonel. Begivenheden omkring E.R. og Tarantino viste, at nyhedstekster kan fungere som æstetisk ballast, der er i stand til kæntre de traditionelle høj-lav æstetiske hierarkier (film vs. tv) på en måde, der har til hensigt at øge den publikumsmæssige markedsandel. Udviklingen af strategier for kabel-logoer demonstrerede at mærkevare eller brand-name tekster er blevet essentielle markedsandelsholdepunkter i multikanalsflimmeret. NBC's hektiske »don't-worry-behappy« rekonfiguration af »networksfamilien« gennem dets nationale logo/identitetskampagne, viste at identificerende tekster kan bruges som selskabsmæssig terapi, der fungerer som en slags fortættede, ubevidste rapporter for aktionærerne, samtidig med at de lindrer usikkerheden og angsten hos de løst-tilknyttede, kapital-søgende regionale stationer.

NBC's omlægning kan endelig også ses som indbegrebet af en »tag-ingen-fanger« tilgang til tv-marketing - baseret som den er på de muligheder, der ligger i en industriel tekst, der konstant forandrer sig. Tænk på hvordan denne kampagne, der havde som formål at forholde sig til ændringer, udviklede sig fra en enkelt kilde. Et lille salgsfremmende spot og nogle interviews blev optaget $\mathrm{i}$ produktionshallerne til brug i pressematerialet på video og til salgsfremmende arbejde overfor journalister fra de trykte medier. Den samme bid film, med god belysning og meningsgivende i sig selv (i modsætning til det kedelige og usammenhængende Betacam videomateriale, der udgør de fleste segmenter i »Today Show «) blev sendt til New York for morgenens talk show, hvor dets fortællestemme blev fjernet og erstattet af værtens friske ordstrøm. Couric brød ind som udsendelsens (og networkets) tilstedeværende æstetiker. Hun gjorde det samtidig muligt for seerne derhjemme at stemme ved at ringe på et gratis telefonnummer og derved forbandt hun den nyfundne, slemme-dreng forretningsboheme på forkant med udviklingen med networkets mere traditionelle populisme. Hele samlingen af nyligt omlagte og fornyede logoer blev også distribueret til de tilknyttede stationer for at blive sendt - som logoer - sammen med noget uddybende (baggrunds-)materiale. Pressematerialets yderligere baggrundsmateriale, "making-of« analysen på video og fotografier fra produktionen var med som en bonus og kunne bruges i hvilket som helst program eller publikation, hvor man kunne ønske at udsende eller trykke materialet. De filmede kunstnerinterview blev også sendt ud i mindre videobrudstykker, der kunne klemmes ind i showbusiness relaterede indslag, underholdningsmagasiner og førstegangsudsendte syndikerede serier fra andre selskaber. Dette færdigpakkede pressemateriale til tv-brug strømmede således igennem flerkanalsmiljøet samtidig med, at selve materialet var under konstant opløsning og forandring.

Men de permuterende marketingtekster udgjorde ikke kun videofoder, der efter produktionen var blevet grafisk opstillet for at blive spredt ud over hele miljøet. En endnu bredere vifte af appropriationer blev sat i gang da NBC, i deres medierende tekster, eksplicit pralede af deres ufor- 
trødne forbindelse til de tilknyttede kunstneres avantgardistiske bagland. Referencer til MTV, til skaberen af Lawnmover Man, Ren and Stimpy, endog til selve 1960'erne i al almindelighed, fik alle disse fænomener til at fremstå som NBC's område. På trods af åbenlys vildledelse gav denne form for industriel-tekstuel definitions-taktik det ellers så sindige NBC mulighed for på en eller anden måde at vere det meget mere hippe Viacom og MTV, og det på trods af den kendsgerning, at NBC networket absolut ingen historiske forbindelser har til fortroppen i kabelverdenen og dens markeds-beviste nytænkning. Dette er således udtryk for den ultimative appropriation på tværs af skillelinjer. Videofragmenter i branchens tilknyttede fora forvandles her til en ekstensiv form for symbolsk appropriation og spredning gennem industrien. Denne form for lavteori fungerer således som en semiotisk klyngebombe. Hvorfor skal man selv forsøge at producere tv's avantgarde, når man blot ad elektronisk vej kan indhylle sig i den?

Mens mange nok vil se dette mønster af muterende og medierende tekster som en simplistisk opdatering, eller (værre) mystifikation af de traditionelle værktøjer, som enhver første-års overbygningsstuderende tilegner sig for at »forske« - en bevidsthed om forskellen på det skrevne ord, levende billeder, primære og sekundære kilder - er det samtidigt åbenlyst, at sådanne medierende tekster er langt mere end blot arkivstumper for den sandhedssøgende forsker. Alle de industrielle-tekstuelle typer, som jeg har nævnt her er i udpræget grad 'offentlige' fænomener, der på en og samme gang er underholdning og baggrundshistorie/ kontekst, der kan engagere læseren i en aktiv læsning. Tv-forskningen bliver nødt til at forstå disse medierende tekster som mere end blot simple produkter af de økonomiske sammenhænge. Sådanne tekster skal snarere ses som en uendelige række permutationer af program og industri, og dermed som analyseobjekter, der er lige så righoldige som 30- og 60-minutters bidder af genreprogrammer, der indtil nu har høstet broderparten af den kritiske opmærksomhed fra historikere og kritikere.

I hvad nogle har kaldt »post-network«-epoken fremkommer tv-kunsten i lige så høj grad i den industrielle brobygning, som den gør på skærmen. Selv i de ideer, der ligger implicit i 500-kanalsmyten (med dens forestilling om seervalg fordelt $i$ et koordinatsystem med x-/y-akser - tidspunkter, kanaler og dage - på ét og samme niveau, altså menuvalg fra et daglig udvalg) er der ingen tegn på forståelsen af, at lav-teoris-medieringerne foregår på en slags z-akse, der træder frem imod publikum i realtid, altså en akse ad hvilken programlæggerne rent faktisk forsøger at gribe fat i seerne uden om og ved siden af det specifikke program. Ethvert valg af en kanalniche fremstår med et væld af mobile og muterende marketingstekster. Disse industrielle medieringer udgør ikke kun selve den rørledning, der gør det muligt at »vælge«. De udgør samtidig en slags elektronisk skyts i og omkring programmerne. Hvad der traditionelt set har været isoleret som kontekst - et område, der typisk har været forbeholdt seriøse historikere - bliver her omformet til underholdning på skærmen, og det over hele kanalspektret. Hvorfor og med hvilket formål seerne opsøger sådanne baggrundshistorier og industriel viden er spørgsmål, der bunder i kulturelle forskelle, og som der bør ofres mere tid på. Extra, Entertainment Tonight, Hollywood business rapporter, lokale nyhedsbegivenheder, network-omlægninger og on-line cyber-chats med producere viser, at marketing ikke længere kun er gud for programlæggerne. Marketing er nu også blevet en væsentlig del af produktionskulturen, industriens æstetik og seernes kompetencer.

Tak til Lennard Højbjerg og Klaus Bruhn Fensen både for deres forskning og for deres invitation til en rakke forelasninger om to på Københavns Universitet $i$ september 1997, hoor blandt andet denne artikel blev presenteret.

\section{Litteratur}

Adorno, T. W., og Horkheimer, M. (1944): Dialectic of Enlightenment, New York: Seabury.

Babcock, B. (1986): »Modeled Selves: Helen Cordero's »Little People««, in: Turner, Victor, og Bruner, Edward (eds.): The Anthropology of Experience, Urbana: University of Illinois Press.

Berger, M., Wallis, B., og Watson, S. (ed.) (1995): Constructing Masculinity, New York: Routledge.

Bhaba, H. K. (1995): »Are You a Man or a Mouse«, in: Berger, M., Wallis, B., og Watson, Simon (eds.) Constructing Masculinity, New York: Routledge. 57-67.

Boon, J. A. (1986): »Symbols, Sylphs, and Siwa: Allegorical Machineries in the Text of Balinese Culture $«$, in: Turner, Victor, og Bruner, Edward (eds.) The Anthropology of Experience, Urbana: University of Illinois Press. 239-260.

Bourdieu, P. (1984): Distinction: A Social Critique of the Fudgment of Taste, Cambridge: Harvard University Press. 
Caldwell, J. (1994): »Performing Style: Industrial Strength Semiotics«, in: Browne, N. (ed.) American Television: New Directions in History and Theory, New York: Harwood Academic.

Caldwell, J. (1995): Televisuality: Style, Crisis, and Authority in American Television, New Brunswick: Rutgers University Press.

Corner, J., Fenton, K., Richardson, N. (1990) Nuclear Reactions, London: John Libbey.

Dayan, D., og Katz, E. (1992): Media Events: The Live Broadcasting of History, Cambridge: Harvard University Press.

Eastman, S., og Klein, R., (1991): Promotion and Marketing for Broadcasting and Cable, Prospect Heights: Waveland Press.

Fiske, J. (1987): Television Culture, New York: Routledge.

Foster, H. (1985): Recodings: Art, Spectacle, Cultural Politics, Port Washington: Bay Press.

Gans, H. (1974, 1975): Popular Culture and High Culture: An Analysis and Evaluation of Taste, New York: Basic Books.

Geertz, C., (1983): Local Knowledge: Further Essays in Interpretive Anthropology, New York: Basic Books.

Gripsrud, J., (1995): The Dynasty Years, New York: Routledge.

Gramsci, A. (1971): Selections From the Prison Notebooks, New York: International Publishers.

Jameson, F. (1983): »Posmodernism and Consumer Society", in: Foster, H. (ed.) The Anti-Aesthetic: Essays in Postmodern Culture, Port Townsend: Bay Press.

Jenkins, H. (1992): Textual Poachers: Television Fans and Participatory Culture, New York: Routledge.

Jensen, K. B., (1995): The Social Semiotics of Mass Communications, London: Sage.

Lasch, C. (1978): The Culture of Narcissism, New York: W.W. Norton.

Lyotard, F. (1984): The Postmodern Condition: A Report on Knowledge, Bloomington: Univ. of Minnesota Press.

Marc, D., og Thompson, R., (1992): Prime Time, Prime Movers, Boston. Little, Brown, and Co.

Meyerhoff, B., (1979): Number Our Days, New York: Dutton.

Meyerhoff, B., (1986): »Life Not Death in Venice«, in: Turner, V., og Bruner, E. (eds.), The Anthropology of Experience, Urbana: University of Illinois Press. 261-287.

Mitchell, W.J.T., (1980): The Language of Images, Chicago: University of Chicago Press.

Newcomb, H., og Hirsch, P. (1983): »Television as a Cultural Forum«, in: Quarterly Review of Film Studies 8: 48-55.

Ohman, R. (ed.), (1996): Making and Selling Culture, Hanover: Wesleyan University Press.

Rorty, R., (1979): Philosophy and the Mirror of Nature, Princeton, NJ: Princeton University Press.

Seiter, E. (1999): Television and New Media Audiences, London: Oxford University Press.

Stam, R. (1992): Reflexivity in Film and Literature: From Don Quixote to Fean Luc-Godard, New York: Columbia University Press.

Turner, V., (1986): »Dewey, Dilthey, and Drama: An Essay in Anthropological Experience«, in: Turner, Victor, og Bruner, Edward, (eds.) The Anthropology of
Experience, Urbana: University of Illinois Press. 33-44.

Turner, V., og Bruner, E., (1986): The Anthropology of Experience, (Urbana: University of Illinois Press.

White, M. (1985) »Television Genres: Intertextuality«, in: Fournal of Film and Video, 38, 41-47.

\section{Noter}

1 Mens Foster (1986) og Stam (1992) forbinder intertekstualiteten med henholdsvis 'subversive' udviklinger indenfor kunstverden og fiktive konstruktioner i narratologien, peger både Jameson (1983) og White (1985) i højere grad på egentlige kulturelle grunde til den omkringsiggribende intertekstualitet. Jameson argumenterer for dens centrale placering i udviklingen af senkapitalismens forbrugerkultur, og White beskriver den som en mekanisme til at højne publikums motivation og kompetence, og derved maksimere seertallene. Men selv om disse fremstillinger forbinder en tekstuel praksis med publikums- og forbrugerøkonomier, forbigår de imidlertid det vigtige felt og/eller problemstillinger, der udspringer af en fokus på det industrielle - et genstandsområde, der relaterer sig til forretnings- og selskabsmæssige såvel som til tekniske faktorer, der på en og samme tid sikrer at intertekstualiteten er både indbringende $\mathrm{og}$ at den på effektiv vis reproduceres.

2 I USA f. eks er forskningmiljøerne inden for massemedier og kommunikation på Syracuse, Indiana, Miami og Georgia universiteterne kendt for deres betydningsfulde arbejde om massemedierne og deres sociale kontekster med afsæt i eksperimentale og socialvidenskabelige tilgange. Ph.D.-overbygningerne inden for tv på USC, NYU og UCLA er alle derimod udsprunget af den filmanalytiske tradition - som er præget af europæisk teori indenfor litteratur, æstetik og semiotik - og har som oftest inkorporeret minutiøse tekstanalyser som et af grundelementerne i deres forskning af både kritisk og historisk karakter. Denne kontekst-vs.-tekst opdeling er ydermere forstærket i akademiske publikationer omhandlende tv. I fournal of Broadcasting and Electronic Media, udgivet af The Broadcast Education Association, er hovedvægten lagt på de eksperimentale og samfundsvidenskabelige paradigmer, mens de tv-relaterede artikler i Cinema fournal, udgivet af The Society for Cinema Studies siden sidst i halvfjerdserne, som hovedregel er udsprunget af en eller anden form for tekstuel tilgang, hvilket også gælder for en række senere poststrukturelle permutationer. Ingen af disse tidsskrifter, hverken i citat eller henvisning, tyder på noget egentlig kendskab til den viden, der udgår fra den anden, parallelle, forskningsverden.

3 I relation det begreb om en hegemonisk kultur, der stammer fra Gramsci (1971), referer termen »genindvinding« [»recuperation«] til den proces hvorigennem modstand, forskellighed og yderliggående 'appropriationer' indkaples og bringes tilbage ind i den dominerende kulturs fold.

4 Indtil midten af tresserne var amerikansk tv kendetegnet ved en effektiv men forholdsvis monoton stil: 'nul- 
punkts' telefilmsproduktion, eller direkte optagelse med tre kameraer. Hen imod slutningen af årtiet var der nogle enkeltstående tilfælde, hvor tv lavede nogle eksplicit stilistiske 'begivenheder' i primetime, men disse var som regel klart 'afgrænsede' indenfor deres respektive programserier som specielle oplevelser eller 'ændrede tilstande' (Caldwell, 1995).

5 Faktisk definerer Marc og Thompson Dragnet ved dets genoplivning af 'McCarthy-æraens ekstremisme' (Marc og Thompson, 1992, 136).

6 PTA organisationer ('Parent-Teacher Associations') blev udbredte og populære fora for den amerikanske middelklasses samfundsengagement i tresserne, hvor en ny forældregeneration fra forstæderne søgte indflydelse i de offentlige skoler for at fremme og beskytte deres børns trivsel.

7 I stedet for at bruge en grundig idebeskrivelse som udgangspunkt for programudvikling starter de fleste programmer i dag med en langt mere fortættet konceptmekanisme: et mundtlig oplæg på to-tre sætninger, der specificerer en series udgangspunkt, kerne og/eller bevægelse i en ultrakort og engagerende form. Hurtigheden og effektiviteten af denne verbale begrebsliggørelse gør det muligt for producere og manuskriptforfattere at dække en stor vifte af fortællemuligheder med meget kort varsel. Denne facon tilgodeser og udnytter let tilgængelige kombinationsmuligheder samt hybrider imellem gamle og nye udsendelser. Denne hurtige verbale tilgang, denne kollageagtige sammenkædning og sparring - der dagligt koreograferes imellem producere og grupper af manuskriptforfattere - sikrer både en vis genremæssig kontinuitet bagud samtidig med at der uundgåeligt sker nok brud fornyelser. Der er blevet argumenteret for, at dette har været en af årsagerne til den mani for stilistisk exces, der har kendetegnet [amerikansk] tv siden firserne.

8 'WGA' er en alment brugt forkortelse for 'the Writer's Guild of America', det forbund, hvis medlemmer skriver hovedparten af manuskripterne til amerikansk primetime tv.

9 I den konkurrencepraksis, der er etableret imellem de amerikanske tv-network, er 'sweep weeks' nogle udvalgte uger i november, februar og maj, der bruges til at fastsætte reklamepriser for programmer på de enkelte networks sendeflade; dette foregår ved at man beregner og sammenligner procentdelen af alle mulige seere og dem, der valgte at se programmet. Selvom den statistiske videnskab der ligger til grund for de 'stikprøver', der benyttes til at beregne 'ratings' og 'shares' langt fra er ufejlbarlig, prøver de fleste network, at tilsætte eller 'hype' programlægningen med 'specials', for at tiltrække kunstigt mange seere i netop denne periode. Ved at blæse seertallene op på denne måde, håber networkene at kunne forlange (kunstigt) høje priser for reklametid i relation til specifikke programmer.

10 Efterspørgslen efter eksplicitte forbindelser mellem fiktionsprogrammer og nyhedsudsendelser er nok større blandt de stationer, der er en del af networks-'familien', end den er blandt de uafhængige stationer, der er mere løst tilknyttet til de syndikat-programmer, som de køber og sender. Uafhængige stationer er dog samtidig eksperter i at udnytte udsendelsen af spillefilm, der spiller en vigtig rolle i disse stationers konstante forsøg på at gøre sig mere synlige.

11 Dette var f. eks et tilbagevendende tema i både officielle paneloplæg og uformelle diskussioner på gangene ved Showbiz Expo i Los Angeles i juni 1997.

12 Det er er vigtigt at gøre opmærksom på den forskelsbehandling, der er imellem de lokale stationer, der ejes af networket NBC, og lokale tilknyttede stationer. De ejede stationer (såsom NBC-4 Burbank) er centreret i store bymæssige områder, og genererer derfor betydelige omsætningsmæssige strømme; disse stationer gennemgik som følge deraf større ændringer mht. navn og logo. De tilknyttede stationer, hvis lokale ejere derimod kun er (midlertidigt) kontraktligt forpligtet til at aftage og sende networkets tilbud (såsom KJRH-2) blev til gengæld tilbejlet af networkenes forherligelse af network-'familien'.

13 NBC havde siden 1950'erne startet dagens programudbud fra networket med to-timers talkshowet/nyhedsudsendelsen The Today Show, der i bund og grund var en blanding af lette nyheder, glad snak og korte features tiltænkt middelklassens morgenduelige og/eller dem, der så tv mens de spiste morgenmad. The Today Show havde af de programansvarlige helt sikkert aldrig været et sted for noget nyt og risikofyldt rettet mod den brede offentlighed.

14 Disse ændringer i manuskriptforfatning og produktion fremkom ved en paneldiskussion ved Showbiz Expo i Los Angeles i juni 1997. Producerne tilføjede - på en måde, der medvirkede til at fremme myten om Hollywoods succes ved at pege på Internettets 'demokrati' - at en af de nyligt ansatte unge netop var blevet fyret fra et sekretærjob hos Disney.

15 Ellen Seiter har analyseret hvordan computermediet og internetadgangen på forhånd gør publikum modtagelig for klassebestemte forpligtelser. På grund af deres disponible indkomst har denne relativt elitære demografiske gruppe nogle værdifulde omsætningsmæssige implikationer for reklamefolk og programplanlæggere. (Seiter, under udgivelse).

16 I forbindelse med den støttegruppe for alkoholikere, der hedder 'Alcaholics Anonymous' [AA], blev 12trins terapien til helbredelse også en udbredt model for helbredelsen af andre former for afhængighed (sygelig trang til mad, pårørendes 'med-'afhængighed af det forhold, der opstår imellem den plejende og den plejede, afhængighed af sex, etc.). I dette afsnit parodierer Nich-at-Nite dette pop-psykologiske selvforbedringsprogram som et teoretisk undergrundsleksikon for den skjulte betydning af den oprindelige tv-tekst.

17 Der refereres her til en bog, der var med til at definere den amerikanske socialpsykologi i 1970'erne, nemlig C. Lasch (1978): The Culture of Narcissism, New York, W. W. Norton. 


\section{Oversætternoter}

a) »Det at tale fra periferien« er en oversættelse efterhånden - i hvert tilfælde indenfor cultural studies - idiomatiske »speaking from the margins«.

Bell hooks er en kendt og anerkendt amerikansk, sort, kvindelig intellektuel, der med sit kritiske arbejde i relation til problemstillinger omkring køn og race i en postmoderne kontekst er centralt - men »oppositionelt« - placeret indenfor den samfundsmæssige og humanistiske (universitets-) debat i USA.

b) MTM er det produktionsselskab, der stod for succes'en The Mary Tyler Moore Show. c) I en bredere forstand refererer »signatur« her til programmer og /eller serier, der umiskendeligt (kan) relateres til en anerkendt tv-producent som f.eks. Nordisk Film og TV.

d) »Fædrelandskonstruktion« er en oversættelse af »nation-building«.

John Caldwell er lektor ved Radio, TV \& Film Department, California State University-Long Beach. 